\title{
A patient with novel mutations causing MEN1 and hereditary multiple osteochondroma
}

\author{
Hanna Remde, Elke Kaminsky ${ }^{1}$, Mathias Werner ${ }^{2}$ and Marcus Quinkler ${ }^{3}$ \\ Charité University Medicine, Berlin, Germany \\ ${ }^{1}$ Laboratory for Molecular Genetics, Hamburg, Germany \\ ${ }^{2}$ Institute of Pathology, HELIOS Klinikum Emil von Behring, Stiftung Oskar-Helene-Heim, Berlin, Germany \\ ${ }^{3}$ Endocrinology in Charlottenburg, Stuttgarter Platz 1, D 10627 Berlin, Germany
}

\author{
Correspondence \\ should be addressed \\ to $\mathrm{M}$ Quinkler \\ Email \\ marcusquinkler@t-online.de
}

\section{Summary}

We report of a male patient aged 32 years who presented with primary hyperparathyroidism. Three parathyroid glands were resected. At the age of 46 years, nervus facialis irritation was noted, and an MRI scan incidentally revealed a non-functioning pituitary adenoma with affection of the chiasma opticum. The patient underwent transsphenoidal operation resulting in pituitary insufficiency postoperatively. At the same time, primary hyperparathyroidism reoccurred and a parathyroid adenoma located at the thymus was resected. The mother of the patient died early due to multiple tumors. The patient was suspected to have multiple endocrine neoplasia type 1 (MEN1) and genetic analysis was performed. In addition, on clinical examination, multiple exostoses were noticed and an additional genetic analysis was performed. His father was reported to have multiple osteochondromas too. MEN1 was diagnosed in the patient showing a novel heterozygote mutation c.2T $>A$ in exon 2, codon 1 (start codon ATG > AAG;p.Met1?) of the MEN1 gene. In genetic mutational analysis of the EXT1 gene, another not yet known mutation c.1418-2A > C was found in intron 5 of the EXT1 gene (heterozygotic). In conclusion, we report novel mutations of the EXT1 and the MEN1 genes causing hereditary multiple osteochondromas and MEN1 in one patient.

\section{Learning points:}

- It is important to ask for the patient's family history in detail.

- Patients with MEN1 are characterized by the occurrence of tumors in multiple endocrine tissues and nonendocrine tissues, most frequently parathyroid (95\%), enteropancreatic neuroendocrine $(50 \%)$, and anterior pituitary $(40 \%)$ tissues.

- Familiar MEN1 has a high degree of penetrance ( $80-95 \%$ ) by the age over 50 ; however, combinations of the tumors may be different in members of the same family.

- Patients with EXT1 gene mutations should be monitored for possible transformation of bone lesions into osteochondrosarcoma.

\section{Background}

We report of a patient who presented with multiple endocrine neoplasia type 1 (MEN1) and multiple osteochondromas.
MEN1 is an autosomal dominant inherited disease (1), caused by germline mutations in the MEN1 gene which is located on 11q13. It typically occurs with tumors of the parathyroid glands, the pancreatic islet cells, and the $\begin{array}{rr}\text { (C) } 2015 \text { The authors } & \text { http://www.edmcasereports.com } \\ \text { Published by Bioscientifica Ltd }\end{array}$ 


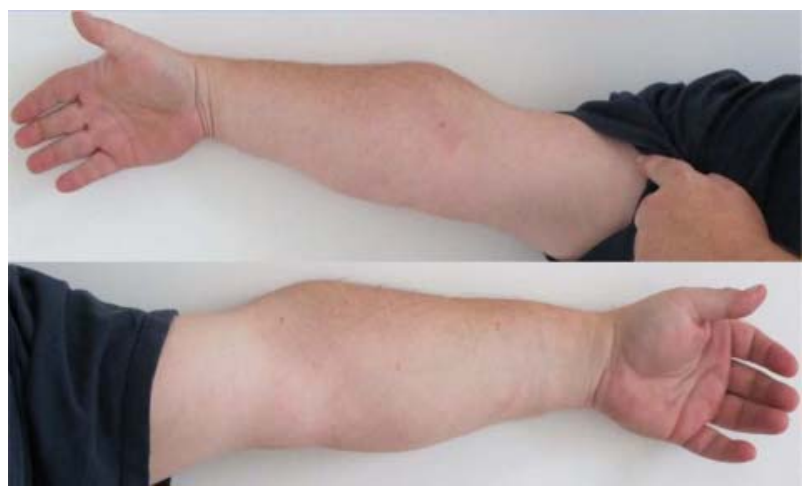

Figure 1

Deformities of the forearms and shortened upper arms of the patient aged 52 years.

pituitary. Less common manifestations include foregut carcinoids, lipomas, angiofibromas, thyroid adenomas, adrenocortical adenomas, angiomyolipomas, and spinal cord ependymomas (2). Bone tumors have not been reported to be associated with MEN1 mutations.

Hereditary multiple osteochondroma (HMO) is an autosomal dominant bone disorder characterized by the presence of multiple benign cartilage-capped tumors. With a prevalence of $\sim 1: 50000$ in western population, osteochondromas are the most common benign bone tumors (3). Two causal genes have been identified, EXT1 and EXT2, which account for 65 and $30 \%$ of cases respectively (4). EXT1 is located on chromosome 8q23q24 (5) and EXT2 on 11p11-p12 (6). Mutations in EXT1 and EXT2 result in insufficient heparin sulfate (HS) biosynthesis. This leads to irregular diffusion patterns of Indian hedgehog $(\mathrm{IHH})$, which plays a major role in enchondral ossification, and hence to abnormal chondrocyte polarization and proliferation (7). Complications that can result from osteochondromas are deformities, functional limitations, compression of nerves and blood vessels, pain due to pressure on neighboring tissues, and most seriously malignant transformation to secondary peripheral chondrosarcoma that occurs in $1-2 \%$ of the cases (4) (8).

\section{Case presentation}

A 46-year-old male patient presented in 2008 to our endocrine outpatient clinic after three weeks of in-patient stay. He was admitted in the hospital due to facial paralysis with gustatory dysfunction. Anamnestically, the patient reported the resection of three parathyroid glands in 1994 due to primary hyperparathyroidism. During his hospital stay, no sound explanation for the quickly remittent partial paralysis of the facial nerve could be determined. However, imaging of the head revealed incidentally a tumor of the pituitary gland. Hormone diagnostics showed suppressed testosterone and IGF1, normal thyrotropin (TSH) with low free-thyroxine ( $\mathrm{fT}_{4}$ ) levels. Basal adrenocorticotropin (ACTH) and cortisol were normal, and prolactin was slightly increased. In the ophthalmological examination, minor changes in the visual field but not in typical bitemporal location were found. However, due to contact and elevation of the chiasma opticum by the tumor, transsphenoidal resection of the non-functioning pituitary macroadenoma was performed. Immunohistochemistry was negative for TSH-, $\mathrm{HGH}-$, PRL-, LH-, FSH-, and ACTH-expression and Mib-1 was $3 \%$. Postoperatively, the patient developed insufficiencies of the gonadotropic, thyreotropic, and corticotropic hormone axes.

In the course, recurrent primary hyperparathyroidism manifested with laboratory changes (PTH: $88 \mathrm{ng} / \mathrm{l}$, calcium: $2.67 \mathrm{mmol} / \mathrm{l}$, phosphate: $1.11 \mathrm{mmol} / \mathrm{l}$ ) and osteoporosis (lumbal spine $t$-score $=-4.1$ ) was diagnosed. A suspicious parathyroid gland was detected in the upper left thymus pole via methoxyisobutyl-isonitril (MIBI)-scintigraphy and resected in June 2008 resulting in hypoparathyroidism postoperatively.

Owing to the suspected diagnosis of MEN1, genetic testing and further diagnostic work-up were initiated. The latter included abdominal ultrasound, gastroscopy, endosonography, abdominal computed tomography (CT), and somatostatin receptor scintigraphy to search for possible neuroendocrine tumors of the gastrointestinal tract. In CT

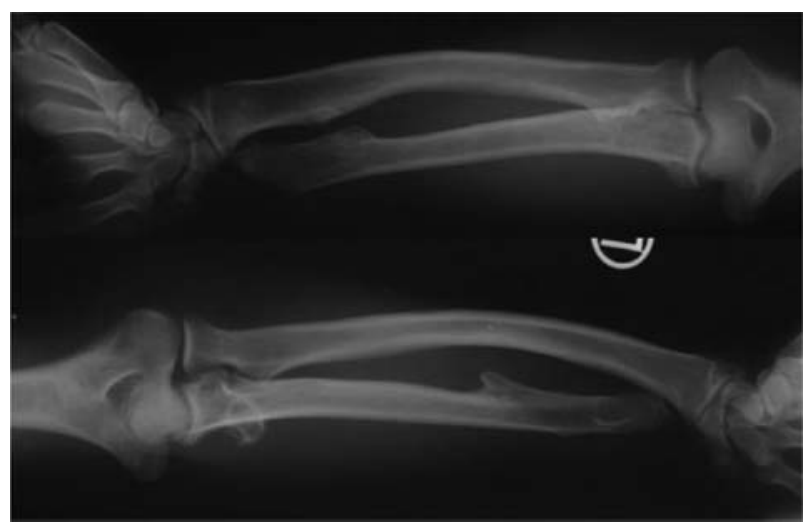

Figure 2

X-ray of both forearms at the age of 17 years with sabre-shaped radius and multiple osteochondromas. 


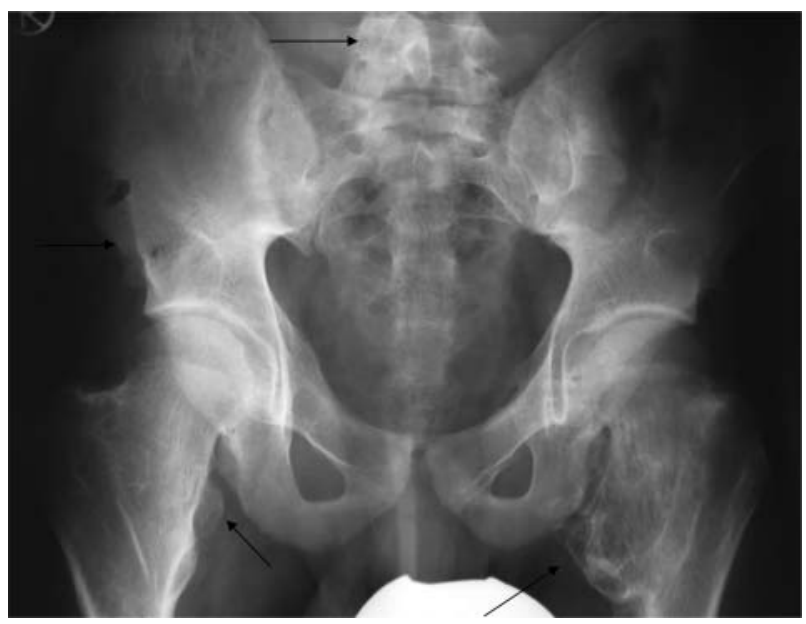

Figure 3

Pelvic overview - impairment of ilium, lumbal vertebra 5 , and both femoral necks at the age of 17 years.

scan, four hyperperfused pancreatic lesions were detected with a maximum diameter of $13 \mathrm{~mm}$. Those lesions were also observed in endosonography presenting as small hypoechogenic areas but not as well-defined spaceconsuming lesions. However, the patient did not have any symptoms of neuroendocrine pancreatic tumors and no suspicious laboratory findings were detected. Genetic testing finally revealed a MEN1 mutation. Taking the patient's family history into account, it could be assumed that his mother suffered and possibly died from MEN1. However, no blood was available from her to confirm the diagnosis. Therefore, there is a very unlikely possibility of a de novoMEN1 gene mutation in our patient.

For further treatment and follow-up, the patient was referred to the endocrine outpatient clinic. During clinical examination of the patient, deformities of the forearms and shortened upper arms were noted (Fig. 1). According to the patient, these skeletal changes existed since early childhood. Reviewing bone X-rays, which were made when he was 17 years old, multiple exostoses, called osteochondromas, of all long bones and some flat bones could be seen (Figs 2 and 3). Neither osteochondromas nor other bone tumors have been reported with MEN1. Reassessing the patient's family history solved this issue. The mother did not have any bone problems, neither bone tumors nor deformities, but the patient's father was reported to have the same kind of bone affections. Thus, an additional genetic disease was made: HMO. In 2011, the patient suffered from increasing pain of the left third rib. An exostosis was removed and histopathological examination revealed an osteochondroma (Fig. 4).

Currently, the patient is in good general health, but occasionally suffers from bone pain. He is not presenting any clinical signs of neuroendocrine tumor. $\mathrm{He}$ is currently on $\mathrm{L}^{-} \mathrm{T}_{4}(125 \mu \mathrm{g} /$ day $)$, testosterone gel (50 $\mathrm{mg} /$ day), hydrocortisone $(10 \mathrm{mg} /$ day), and calcitriol (0.25 up to $0.5 \mu \mathrm{g} /$ day). The pancreatic findings are monitored on a regular basis with MRI and sonography.

\section{Discussion}

The mutation in the MEN1 gene found in our patient has not been described before (Fig. 5). However, for this position of the MEN1 gene mutation, another base exchange has been reported leading to an M1V exchange (9). Villablanca et al. described mutation to be associated with isolated primary hyperparathyroidism in the examined family. This stands in contrast with our observation, as our patient also presents with pituitary adenoma, lipomas, and possible pancreatic tumors. For our mutation, the possible outcomes are that either the protein is shorter, being another methionine used by the translation machinery, or the protein is not formed at all.

Moreover, the EXT1 gene mutation has not been described before (Fig. 5). The EXT1 mutation is located in the acceptor site of intron 5 and presents with a relatively severe phenotype. Nevertheless, a mutation in the same place in the EXT1 gene with another base exchange (A $>\mathrm{G}$
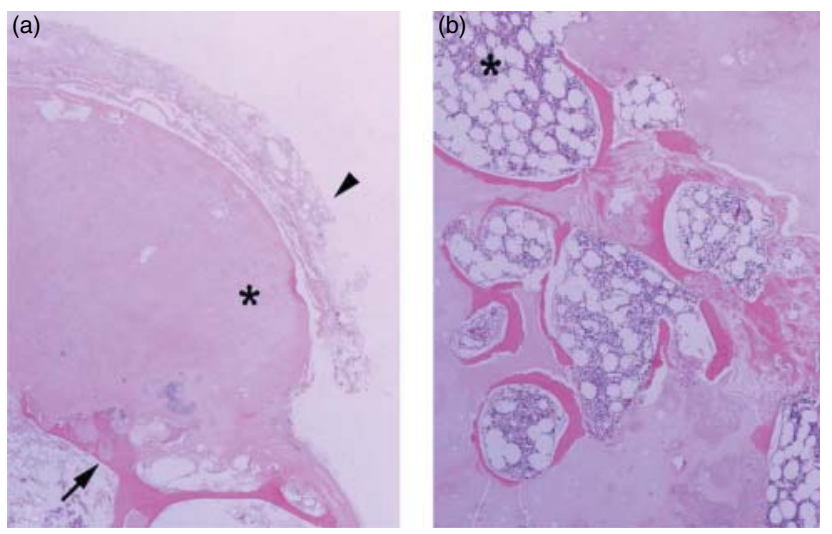

\section{Figure 4}

Histological picture of a removed symptomatic osteochondroma of the third left rib at the age of 49 years, (a) cartilaginous cap $<2 \mathrm{~cm}$ (asterisk) with perichondrium (arrowhead) and cancellous bone at the base (arrow), (b) link between cartilage and bone at the base of the cap, marrow spaces with hematopoiesis (asterisk). 


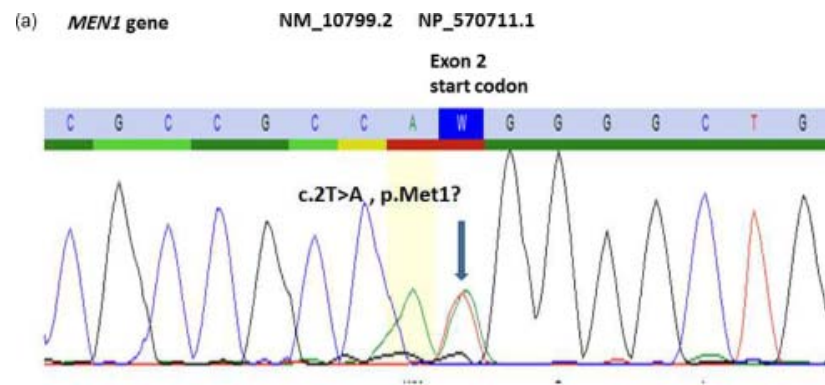

(b)

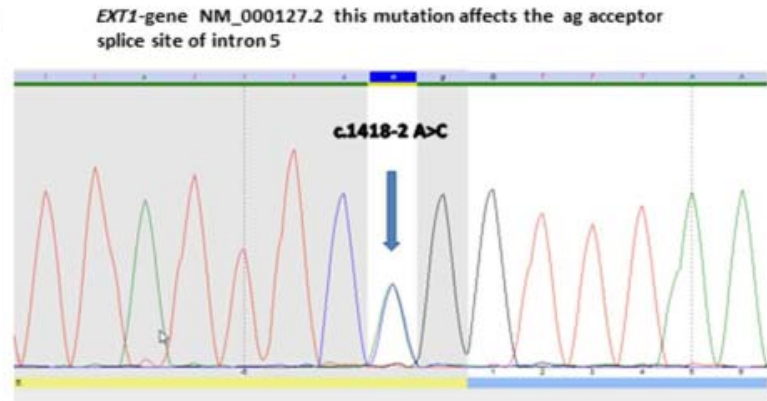

Figure 5

Genetic sequencing of the (a) MEN1 gene and the (b) EXT1 gene revealing the patient's mutations. Molecular analysis was performed as follows: peripheral blood for germline DNA analysis was drawn from the patient after written informed consent was obtained. Genomic DNA was extracted from peripheral blood leukocytes using QIAmp DNA blood Mini Kit (Qiagen $\mathrm{GmbH}$ ). The coding regions of the MEN1 and EXT1 gene and exon-intron boundaries were amplified by polymerase chain reaction and were directly sequenced using the Sanger method. Mutations are described according to the current mutation nomenclature guidelines (http://www.hgvs.org).

instead of $\mathrm{A}>\mathrm{C}$ ) has been reported by Dobson-Stone $\mathrm{et}$ al. (10). We performed genetic testing in the father and detected the same mutation in the EXT1 gene (the father did not harbor a mutation in the MEN1 gene). By using in silico prediction (integrated Software Alamut V.2.4, Interaktive Biosoftware http://www.interactive-biosoftware.com) for the EXT1 splicing mutation, we predict that EXT1 mutation c.1418-2A >C activates an exonic cryptic acceptor splice site (ASS) of exon 6. In that case, the patient had 'three or more radiographically confirmed osteochondromas' (10). In our case, the mutation is related to a severe phenotype, involving upper and lower limbs as well as axial bones (scapula, humerus, ulna, radius, hand bones, femur, tibia, fibula, foot bones, ribs, spine, and pelvis), where multiple osteochondromas and deformities (shortened humerus, sabre-shaped radius as shown in Figs 1 and 2) were observed. The patient needs to be monitored not only regarding possible neuroendocrine tumors in pancreas and gastrointestinal region, but also for a possible transformation of bone lesions into secondary peripheral chondrosarcoma. Therefore, the patient should be informed that growth and increasing pain are suspicious of sarcomatous transformation.

In conclusion, we report mutations in the MEN1 gene and the EXT1 gene found in one patient, which have not been described in the literature yet.

\section{Declaration of interest}

The authors declare that there is no conflict of interest that could be perceived as prejudicing the impartiality of the research reported.

\section{Funding}

This research did not receive any specific grant from any funding agency in the public, commercial or not-for-profit sector.

\section{Patient consent}

Written informed consent was obtained from the patient.

\section{Author contribution statement}

$\mathrm{H}$ Remde analyzed the patient's files and records, scanned the X-rays, and wrote the article. E Kaminsky performed the gene analysis and helped with the discussion. M Werner performed the histological analysis and helped with the discussion. M Quinkler treated the patient, planned the case reports, and wrote the article.

\section{References}

1 Trump D, Farren B, Wooding C, Pang JT, Besser GM, Buchanan KD, Edwards CR, Heath DA, Jackson CE, Jansen S et al. 1996 Clinical studies of multiple endocrine neoplasia type 1 (MEN1). Quarterly Journal of Medicine 89 653-669. (doi:10.1093/qjmed/89.9.653)

2 Chandrasekharappa SC, Guru SC, Manickam P, Olufemi SE, Collins FS, Emmert-Buck MR, Debelenko LV, Zhuang Z, Lubensky IA, Liotta LA et al. 1997 Positional cloning of the gene for multiple endocrine neoplasia type 1. Science 276 404-407. (doi:10.1126/science.276.5311.404)

3 Schmale GA, Conrad EU \& Raskind WH 1994 The natural history of hereditary multiple exostoses. Journal of Bone and Joint Surgery. American Volume 76 986-992.

4 Sarrión P, Sangorrin A, Urreizti R, Delgado A, Artuch R, Martorell L, Armstrong J, Anton J, Torner F, Vilaseca MA et al. 2013 Mutations in the EXT1 and EXT2 genes in Spanish patients with multiple osteochondromas. Scientific Reports 3 1346. (doi:10.1038/srep01346)

5 Lüdecke HJ, Ahn J, Lin X, Hill A, Wagner MJ, Schomburg L, Horsthemke B \& Wells DE 1997 Genomic organization and promoter structure of the human EXT1 gene. Genomics 40 351-354.

6 Wuyts W, Van Hul W, De Boulle K, Hendrickx J, Bakker E, Vanhoenacker F, Mollica F, Ludecke HJ, Sayli BS, Pazzaglia UE et al. 1998 Mutations in the EXT1 and EXT2 genes in hereditary multiple exostoses. American Journal of Human Genetics 62 346-354. (doi:10.1086/301726)

7 Jochmann K, Bachvarova V \& Vortkamp A 2014 Heparan sulfate as a regulator of endochondral ossification and osteochondroma development. Matrix Biology 34 55-63. (doi:10.1016/j.matbio.2013. 11.003) 
Endocrinology

Diabetes \& Metabolism

CASE REPORT
H Remde and others

Novel mutations causing

MEN1 and HMO
ID: 14-0120; March 2015

DOI: 10.1530/EDM-14-0120
8 Sonne-Holm E, Wong C \& Sonne-Holm S 2014 Multiple cartilaginous exostoses and development of chondrosarcomas - a systematic review. Danish Medical Journal 61 A4895.

9 Villablanca A, Wassif WS, Smith T, Höög A, Vierimaa O, Kassem M, Dwight T, Forsberg L, Du Q, Learoyd D et al. 2002 Involvement of the MEN1 gene locus in familial isolated hyperparathyroidism. European Journal of Endocrinology 147 313-322. (doi:10.1530/eje.0.1470313)
10 Dobson-Stone C, Cox RD, Lonie L, Southam L, Fraser M, Wise C, Bernier F, Hodgson S, Porter DE, Simpson AH et al. 2000 Comparison of fluorescent single-strand conformation polymorphism analysis and denaturing high-performance liquid chromatography for detection of EXT1 and EXT2 mutations in hereditary multiple exostoses. European Journal of Human Genetics 8 24-32. (doi:10.1038/sj.ejhg. 5200409)

Received in final form 30 January 2015

Accepted 25 February 2015 